\title{
A IMPORTÂNCIA DA EMPRESA SOCIAL NA MANUTENÇÃO DOS DIREITOS FUNDAMENTAIS DA PESSOA HUMANA
}

\author{
THE IMPORTANCE OF SOCIAL ENTERPRISE IN MAINTAINING THE \\ FUNDAMENTAL RIGHTS OF THE HUMAN PERSON
}

\author{
Ivan Dias da Motta ${ }^{1}$ \\ Horácio Monteschio ${ }^{2}$ \\ Flávia Jeane Ferrari ${ }^{3}$
}

\begin{abstract}
Resumo:
O presente trabalho objetiva determinar a importância da empresa social no âmbito da manutenção dos direitos fundamentais da pessoa humana. A temática justifica-se diante do contexto de desigualdade social e pobreza em que ainda se encontra o Brasil, bem como pela insuficiência do Estado para suprir as necessidades básicas da população, necessidades essas previstas pela Declaração Internacional dos Direitos Humanos e na Constituição Federal de 1988. Foi desenvolvida uma pesquisa de procedimento bibliográfico, de modo a estabelecer a construção e disseminação dos termos relacionados a empresa social, bem como seu significado. Posteriormente a empresa social é tratada no âmbito dos países emergentes especialmente o Brasil, à luz da legislação e de sua relevância diante dos problemas socioeconômicos desses países. $O$ trabalho concluiu que as empresas sociais desempenham um papel fundamental quanto a manutenção dos direitos humanos, seja em suas atividades próprias ou através da função social de empresas privadas.
\end{abstract}

Palavras-chave: Empresa social. Direitos Humanos. Constituição Federal. Desigualdades sociais. Função social.

\footnotetext{
${ }^{1}$ Possui graduação em Direito pela Universidade Estadual de Maringá (1996), mestrado em Direito das Relações Sociais pela Pontifícia Universidade Católica de São Paulo (1998) e doutorado em Direito das Relações Sociais pela Pontifícia Universidade Católica de São Paulo (2000), Pós-doutorado em Direito Educacional pela Pontifícia Universidade Católica de São Paulo (2001). Atualmente é professor permanente do Programa de Mestrado em Direito do Centro Universitário de Maringá, integrando a linha de pesquisa "A Tutela Constitucional e Privada dos Direitos da Personalidade nas Relações Privadas". Possui atuação profissional na área da advocacia e consultoria em Direito Educacional.

2 Pós-Doutor na Universidade de Coimbra - Portugal e pelo UNICURITIBA, Paraná - Brasil. Doutor em Direito pela Faculdade Autônoma de São Paulo- FADISP. Mestre em Direitos da Personalidade - UNICESUMAR. Professor do Programa de mestrado da UNIPAR.

${ }^{3}$ Mestranda em Direito Empresarial e Cidadania pelo Unicuritiba (2019). Especializações nas áreas de Ministério Público \& Estado Democrático de Direito (2019); Direito Militar (2018); Processo Civil (2017); Direito Ambiental (2017); Direito do Trabalho (2013) e Bel. Direito pela Facear (2012). Integrante do Programa Institucional de Iniciação Científica - PCI junto ao Centro Universitário Curitiba - Unicuritiba, Linha de Pesquisa: Compliance (2019). Cal Membro da Comissão para Combate à Corrupção do LIONS Club Curitiba Batel. Experiência na área jurídica como Assessora de Magistrado, Escrevente Juramentada, Conciliadora, Juíza de Paz, Professora, Perita e Avaliadora nas áreas de Meio Ambiente e Imobiliária. Atualmente sou Adjunta da Seção de Sindicância, Processos Administrativos e IPM, da Assessoria de Apoio para Assuntos Jurídicos da $5^{\text {a }}$ Região Militar - $5^{\text {a }}$ Divisão de Exército. E-mail: flaviajeane.ferrari@hotmail.com.
} 


\begin{abstract}
:
This work aims to determine the importance of social enterprise in the context of maintaining the fundamental rights of the human person. The theme is justified by the context of social inequality and poverty in which Brazil still finds itself, as well as by the State's insufficiency to meet the basic needs of the population, needs provided for in the International Declaration of Human Rights and in the Federal Constitution of 1988 A bibliographic procedure search was carried out in order to establish the construction and dissemination of terms related to social enterprise, as well as their meaning. Subsequently, the social enterprise is treated in the scope of the emerging countries - especially Brazil, in light of the legislation and its relevance in the face of the socioeconomic problems of these countries. The work concluded that social companies play a fundamental role in maintaining human rights, either in their own activities or through the social function of private companies.
\end{abstract}

Keywords: Social enterprise. Human rights. Federal Constitution. Social differences. Social role.

\title{
INTRODUÇÃO
}

As chamadas empresas sociais agregam a si um caráter híbrido por objetivar o lucro e fins para a promoção do bem social. Também são chamadas de empresas socias as organizações sem fins lucrativos. Estas, por sua vez, desempenham sua missão através de atividades comerciais ou são exclusivamente dependentes de doações para sua manutenção (ROSOLEN; TISCOSKI; COMINI, 2014).

Os primeiros termos para definir esse tipo de instituição surgiram na Europa, na última década do século XX e foram se ampliando, surgindo discussões e correntes de concepções europeias, americanas e nos países emergentes. Nestes últimos - e no Brasil, mesmo sem haver uma regulamentação legal estabelecida, as empresas sociais tomaram maior enfoque, uma vez que as mesmas passaram a ser vistas como um instrumento poderoso de combate às desigualdades sociais na base da pirâmide (DEFOURNY, 2004)

Nesse contexto, o pergunta-se: como a atuação da empresa social em um país emergente pode contribuir para a manutenção e promoção dos direitos fundamentais? Dessa maneira, o objetivo geral do presente trabalho é determinar a importância da empresa social no âmbito da manutenção dos direitos fundamentais da pessoa humana. Como objetivos específicos, pretende-se: compreender as origens e atribuições ao termo empresa social; discutir a questão da regulamentação e/ou princípios regulatórios da empresa social no Brasil; entender como as ações da empresa social podem promover os direitos fundamentais. 
O interesse pela temática abordada justifica-se diante da notável insuficiência do Estado para suprir todas as necessidades da população e garantir a todas as pessoas vida digna, com trabalho, moradia, saneamento básico, educação e saúde, entre outros recursos fundamentais à vida humana.

Assim, o presente trabalho desenvolve uma pesquisa de abordagem qualitativa, de procedimento bibliográfico. Dessa maneira, foram realizados pesquisas e estudos acerca da teoria da empresa social, sua definição, origens e preceitos legais ou regulatórios, com o intuito de compreender a importância destas instituições na preservação dos direitos fundamentais das pessoas mais necessitadas da sociedade. A pesquisa desenvolvida, bem como as conclusões alcançadas foram desenvolvidas sem que houvesse quantificação de valores ou dados específicos. Foram considerados livros, artigos de revistas e periódicos no âmbito do Direito, teses, dissertações, jurisprudência, além de documentos regulatórios e tratados interacionais 


\section{A TEORIA DA EMPRESA SOCIAL}

O termo empresa social possui diversas variantes, dependendo de sua aplicação, contexto e abordagem teórica. As mais conhecidas são negócios inclusivos, negócios sociais e a própria empresa social. Há de se salientar que o negócio social é o termo empregado mais comumente no âmbito nacional brasileiro (COMINI; BARKI; AGUIAR, 2012).

As empresas que se encaixam nessas definições, genericamente, tratam-se de negócios que atuam não somente apenas em função do lucro e crescimento próprio, mas também levam em consideração uma responsabilidade com o setor do desenvolvimento social.

As autoras Rosolen, Tiscoski e Comini (2014, p. 3) definem de forma simplificada as empresas sociais, classificando-as de acordo com seus objetivos finais:

\footnotetext{
Empresas sociais podem ser definidas como empresas de duplo propósito e que adequam metas de lucro com objetivos sociais (híbridas), ou organizações sem fins lucrativos empenhadas em desenvolver atividades comerciais que ofereçam suporte a execução de sua missão (organizações com fins sociais) (ROSOLEN; TISCOSKI; COMINI, 2014, p. 3).
}

De acordo com Defourny (2004), as primeiras discussões e conceitualizações acerca da empresa social surgiram recentemente, em 1990, a partir das publicações da revista italiana Impresa Sociale. Outros países que se tornaram também polos de discussão do tema na década de 1990 foram os Estados Unidos e o Reino Unido.

Posteriormente, a crescente preocupação com as desigualdades sociais, a marginalização e a pobreza no âmbito mundial estenderam a discussão sobre o caráter social das empresas também para os países em desenvolvimento (JÕ̃O, 2014).

Porém no Brasil, ainda atualmente pouco se discute sobre o assunto, sendo que existem apenas algumas dezenas de trabalhos publicados sobre o tema com origem nacional. No cenário internacional dos países emergentes esse cenário não é tão diferente, uma vez que as apenas cerca de $10 \%$ das publicações relacionadas ao tema têm origem em tais países (COMINI; BARKI; AGUIAR, 2012).

Visto que cada país onde emergiu o conceito de empresa social tratam o mesmo sob perspectivas bem características, é válido destacar tais correntes de pensamento para a melhor compreensão geral do assunto. 


\subsection{As empresas sociais europeias}

Assim, partindo das origens do conceito, na perspectiva europeia, o termo mais utilizado é a própria empresa social. Na Europa, o período compreendido entre os anos finais da década de 1970 até a década de 1990 foi marcado por uma considerável crise econômica, bem como nos demais países do mundo, influenciada, entre outros fatores, pela Crise do Petróleo de 1979 (DAVISTER; DEFOURNY; GRÉGOIRE, 2004).

A ocorrência desta crise ocasionou uma série de consequências econômicas e sociais na Europa e no mundo todo. Especialmente no continente europeu, houve muitas demissões em massa, aumentando muito o desemprego e houveram sanções a serviços oferecidos pelos Estados à população.

Dessa forma, as pessoas sofreram prejuízos em todas as escalas, fazendo decair a qualidade de vida e limitando o acesso da população aos serviços mais básicos. Diante dessa situação, diversas empresas passaram ou surgiram com intuitos diversos, como de intervir no setor social, buscando meios para amenizar a situação de crise em que a sociedade da época estava imersa (JOÃO, 2014).

Essas intervenções vieram de empresas que foram fundadas em sua maioria por integrantes civis da sociedade, justamente porque era do interesse destes desenvolver estratégias eficientes para reduzir as desigualdades sociais, os preconceitos e a marginalização de determinadas minorias sociais.

Nesse sentido, segundo Davister, Defourny e Grégoire (2004), uma das maiores e mais evidentes empresas sociais europeias surgidas nesse período foram as Work Integration Social Enterprise. As WISE ficaram conhecidas justamente por apresentar determinados meios de integração ao setor empresarial dos membros da sociedade mais desfavorecidos até então.

Cabe assim destacar alguns destes principais mecanismos de integração que se disseminaram nesse período no continente europeu: ocupação transitória; criação de empregos autofinanciados permanentes; integração profissional com subsídios permanentes e socialização através de uma atividade produtiva.

De acordo com Davister, Defourny e Grégoire (2004), o meio da ocupação transitória tinha por intuito proporcionar um período para aquisição de experiência no mercado de trabalho, ou seja, uma ocupação transitória, justamente porque diferencia-se de um trabalho, um emprego tradicional. Nas palavras dos autores: 
na Bélgica ou as empresas de integração em Portugal oferecem aos estagiários a possibilidade de melhorar as suas competências pessoais, sociais e profissionais, ou seja, aumentar a sua empregabilidade. no mercado de trabalho (DAVISTER; DEFOURNY; GRÉGOIRE, 2004, p. 4).

Dessa forma, através das ocupações transitórias, conhecidas como estágios, as WISE possibilitavam a integração de pessoas que não possuíam prévia experiência em determinados setores, proporcionando assim a melhora das possibilidades de contratação formal e inserção dessas pessoas no mercado de trabalho.

Já a criação dos empregos autofinanciados permanentes criavam empregos estáveis de médio prazo para pessoas que tinham dificuldades de entrar no mercado de trabalho, ou desfavorecidas. No início do trabalho, haviam subsídios do governo ou da própria empresa, destinados a suprir as deficiências de produtividade iniciais (JOÃO, 2014).

À medida que os funcionários vão adquirindo experiência e se aperfeiçoando nas funções, os subsídios vão sendo reduzidos proporcionalmente, principalmente quando esses subsídios são de origem pública. Seja como for, tais subsídios são importantes durante o período inicial na ocupação e dão a oportunidade para que os trabalhadores se tornem competitivos no mercado de trabalho (DAVISTER, DEFOURNY E GRÉGOIRE, 2004).

Quanto a essa modalidade das WISE, os autores Davister, Defourny e Grégoire (2004) citam exemplos desse tipo de integração na França, Alemanha e Reino Unido:

Esse tipo de integração pode ser ilustrado pelo exemplo das empresas de integração
de trabalho de longo prazo (França), que oferecem aos trabalhadores desempregados
um emprego de longo prazo, a fim de permitir-lhes adquirir autonomia social e
profissional e prosperar como "atores econômicos" dentro uma estrutura de gestão
participativa. Da mesma forma, as empresas sociais na Alemanha e no Reino Unido
criam, para os trabalhadores em integração, empregos sustentáveis em um contexto
empresarial bastante clássico. Em todas essas WISEs, o financiamento é
principalmente garantido pelos recursos de mercado derivados da venda dos bens e
serviços produzidos pelas empresas. Onde existem subsídios públicos, eles diminuem
com o tempo ou são para fins específicos (treinadores, equipe de orientação etc.)
(DAVISTER; DEFOURNY; GRÉGOIRE, 2004, p. 4-5).

Haviam WISE europeias que também ofereciam subsídios permanentes a funcionários que por ventura tivessem mais dificuldades de ingressar e permanecer no mercado de trabalho de maneira estável. São os casos de WISE que empregavam pessoas portadoras de deficiência física ou mesmo indivíduos eram marginalizados ou com sérias desvantagens sociais e tinham dificuldades de conseguir um emprego estável.

De acordo com os autores: 
Graças a subsídios públicos significativos, oficinas protegidas (Portugal, Suécia e Irlanda) e empresas de trabalho adaptadas (Bélgica) puderam oferecer várias atividades para pessoas com deficiência física ou mental. Este trabalho permite que eles construam uma "identidade social" e também para adquirir algumas competências profissionais (DAVISTER; DEFOURNY; GRÉGOIRE, 2004, p. 6).

Embora essas WISE tenham representado um grande avanço para as empresas sociais, notou-se que apenas alguns trabalhadores advindos destas empresas "adaptadas" conseguiram ingressar no mercado tradicional de trabalho posteriormente.

A modalidade de socialização através de uma atividade produtiva não se trata exclusivamente de uma integração profissional como são a rigor as anteriores. Essa forma é mais uma ressocialização de determinadas pessoas e não tem a si agregada um contrato de trabalho formal ou uma regulamentação específica (MARTINHO, 2018).

As pessoas enquadradas nessas modalidades são portadoras de graves deficiências (intelectuais ou físicas) ou possuem problemas sociais agravados, como no caso de expresidiários, alcoólatras e usuários de drogas ilícitas, por exemplo (DAVISTER; DEFOURNY; GRÉGOIRE, 2004).

Nesse mecanismo, existiam centros de adaptação à vida profissional que antes de tudo tinham por intuito socializar essas pessoas com graves problemas sociais e/ou deficiências psíquicas, antes de estipular qualquer meta de produtividade. Os autores exemplificam essa modalidade empresa social por meio de alguns casos nos países europeus:

[...] as WISEs com atividades de reciclagem na Bélgica recrutam pessoas com sérios problemas sociais para trabalhar na recuperação e reciclagem de resíduos, com o objetivo de lhes devolver um certo nível de autonomia social e profissional. Finalmente, os centros ocupacionais na Espanha oferecem terapia ocupacional e serviços sociais e pessoais adaptados a pessoas com sérias deficiências e que, portanto, não conseguem encontrar trabalho no mercado de trabalho aberto (DAVISTER; DEFOURNY; GRÉGOIRE, 2004, p. 7).

Logo, ainda que apenas dentro das WISE, essas pessoas tinham a oportunidade de se inserir no mercado de trabalho e desenvolver uma profissão, encontrando assim uma atividade não apenas ocupacional, mas que lhes dava alguma autonomia econômica e social.

\subsection{As empresas sociais americanas}

No meio americano, as empresas sociais são conhecidas pelo termo "negócio social". Essa modalidade de instituição nos Estados Unidos está intimamente relacionada com as organizações sem fins lucrativos (ONG). Essas ONGs foram estimuladas através da contratação das mesmas para que realizassem serviços diversos. Tais instituições eram contratadas 
principalmente pelos governos, entretanto com as crises do início da década de 1980 os recursos destinados a elas foram reduzidos e seus serviços comprometidos (JOÃO, 2014).

Dessa forma, essas organizações tiveram que passar a desenvolver atividades comerciais, como forma de manterem suas funções sociais, tornando-se assim os chamados negócios sociais. Ou seja, tinham uma atividade econômica estruturada, mas que, ao mesmo tempo permitia o desenvolvimento de suas funções com o meio social (KELIN, 2006).

Nessa linha, João (2014, p. 25) define o negócio social enquanto corrente americana:

é uma empresa que se orienta por princípios gerenciais para enfrentar uma necessidade social e/ou ambiental, fornecendo um bem comercial ou serviço, não necessariamente ligado à sua missão, em um ambiente de mercado competitivo, como estratégia para apoiar a sua missão social (JOÃO, 2014, p. 25)

Dees (1998) aponta que os negócios sociais também seguiram uma tendência de buscar meios de se manter competitivos no mercado como uma maneira de serem menos dependentes de caridade, doações ou ajudas por parte de outras instituições e governos. Isso levou as instituições a focarem em aumentar sua competitividade e inovação em serviços, de modo a terem uma renda mais autossustentável e menos vulnerável.

Nessa mesma linha, Abu-Saifan (2012) determina uma identidade do empreendedor do negócio social:

\footnotetext{
O empreendedor social é um indivíduo motivado por uma missão que usa um conjunto de comportamentos empresariais para agregar valor social aos menos privilegiados, tudo isso através de uma entidade orientada para o empreendedor que é financeiramente independente, autossuficiente ou sustentável (ABU-SAIFAN, 2012, p. 6).
}

Uma vez que essas instituições passaram a entrar no mercado, elas também sofreram influência do Capitalismo e do acirramento crescente da concorrência em cada setor. Assim, com abordagem mais comercial, os negócios sociais americanos também passaram a fazer uso de seu caráter e sua missão social para estimular o consumo de seus produtos e serviços, tornando-as mais competitivos e sustentáveis (JONES; KOENIG, 2018).

\subsection{As empresas sociais nos países emergentes}

Nos países emergentes da América Latina e Ásia os termos empresa e negócio social são mais corriqueiramente empregados. Nesses países, a ideia da empresa social surge sob uma perspectiva emergencial de valorização de mecanismos que promovam a melhora nas condições 
de vida, desenvolvimento humano e redução das altas taxas de pobreza (JOÃO, 2014).

Essa ideia surge num contexto de desemprego, de marginalização e exclusão social de indivíduos, crises, ineficiência do amparo governamental aos menos favorecidos, corrupção, má distribuição de riquezas e demais fatores que dificultam o crescimento destes países, principalmente o Brasil (MÁRQUEZ; REFICCO; BERGER, 2010).

No Brasil, de acordo com Ashoka Empreendedores Sociais e Mckinsey, Inc. (2001), as empresas sociais em origem tratavam-se mais de ONGs com subsídios internacionais atuando nas situações de vulnerabilidade social do país. Posteriormente, tais ONGs sofreram restrições dessas verbas tanto dos financiadores externos como dos recursos estatais. Assim, a iniciativa privada passou a subsidiar as ações sociais dessas entidades com o intuito de cumprir ou "terceirizar" suas próprias responsabilidades sociais.

Sob um olhar mais inclusivo e menos vitimizador, Oliveira (2004) destaca que há também empreendimentos brasileiros que partem da premissa de integrar indivíduos excluídos da sociedade às suas atividades, de modo a permitir que estas pessoas possam se aperfeiçoar e ter mais dignidade diante da sociedade e no próprio mercado de trabalho formal.

Essa linha de compreensão leva à visão de empresa social entendida por Muhammad Yunus, que compreende que o combate à pobreza no mundo está no ato de bem direcionar o lucro e ações benéficas à população. Os autores explicam:

\footnotetext{
Assim, uma empresa social é projetada e dirigida como um empreendimento, com produtos, serviços, clientes, mercados, despesas e receitas: a diferença é que o princípio da maximização dos lucros é substituído pelo princípio do benefício social. Em vez de acumular o maior lucro financeiro possível - para ser desfrutado pelos investidores - , a empresa social procura alcançar objetivos sociais (YUNUS; WEBER, 2008, p. 37).
}

Nesse sentido, as empresas passaram a focar suas estratégias em alcançar o público chamado de "base da pirâmide", ou seja, aqueles com as condições de consumo mais limitadas. As empresas viram nessa população um potencial econômico, tendo em vista que sua pobreza decorria da falta de acesso a recursos e bens fundamentais para sua sobrevivência e crescimento (SOUZA; DA SILVA, 2019).

Esse tipo de atuação econômica voltada à população de baixa renda vai justamente de encontro com os princípios de atuação dos negócios sociais, evidenciando o seu potencial de mercado e de empresa com função social (MORAES, 2005).

A organização Artemisia ${ }^{4}$, que incentiva a criação e divulgação de negócios sociais no

\footnotetext{
${ }^{4}$ Disponível em: https://artemisia.org.br/quemsomos/. Acesso em: 24 fev. 2020.
} 
Brasil, fundada em 2004, destaca algumas das características presentes nesses negócios sociais. Essas características também são citadas nas Diretrizes estratégicas para Atuação no mercado de negócios sociais do Serviço Brasileiro de Apoio às Micro e Pequenas Empresas (SEBRAE):

I. Vende um produto ou serviço que contribui para melhorar a qualidade de vida da população de baixa renda;

II. Esse produto ou serviço principal é capaz de sustentar financeiramente a empresa, de forma que ela não dependa de doações ou captação de recursos para as suas operações;

III. Apresenta inovação no modelo de negócio (por exemplo, no modelo de distribuição, no produto ou serviço, no sistema de precificação);

IV. Tem potencial de alcançar escala e opera de maneira eficiente;

V. Há comprometimento do empreendedor e de sua equipe em melhorar a qualidade de vida da população de baixa renda.

Assim, no âmbito nacional, a área de atuação dos negócios sociais é bastante vasta, tendo em vista as dificuldades sociais enfrentadas no país. De acordo com as Diretrizes estratégicas para Atuação do SEBRAE no mercado de negócios sociais (SEBRAE, 2013), os setores prioritários para a atuação dos negócios sociais no Brasil são: água e saneamento básico; agricultura; educação; artesanato; energia; habitação; meio-ambiente; canais de distribuição (meios de comercialização); cultura; tecnologia de informação e comunicação; turismo; saúde e serviços financeiros/micro finanças.

Além disso, um negócio social deve prezar pela sustentabilidade e desenvolvimento locais, incentivar e promover potenciais econômicos e talentos, viabilizar uma economia solidária, respeitar tradições, costumes e a religião, entre outros aspectos (SEBRAE, 2013).

\section{A EMPRESA SOCIAL À LUZ DA LEGISLAÇÃO BRASILEIRA}

No contexto nacional, os negócios sociais, por serem recentes no cenário brasileiro, ainda não possuem uma legislação específica, embora já em seu artigo $1^{\circ}$, a Constituição Federal (CF) de 1988 já estabelece os fundamentos básicos sobre os quais a doutrina se pautará a respeito de qualquer temática. Tais princípios são: a soberania; a cidadania; a dignidade da pessoa humana; os valores sociais do trabalho e da livre iniciativa e o pluralismo político (BRASIL, 1988).

Assim, ainda que a CF não defina princípios para os negócios sociais, os fundamentos 
da legislação supracitados já estabelecem as premissas as quais tais negócios - e todos os demais empreendimento - devem observar em suas atividades.

Além disso, a Constituição Federal estabelece ainda, em seu artigo 170, os princípios fundamentais das atividades econômicas no território nacional. Tais princípios, embora não específicos às empresas sociais, são condizentes com os seus ideais. Em termos, a CF/88 institui:

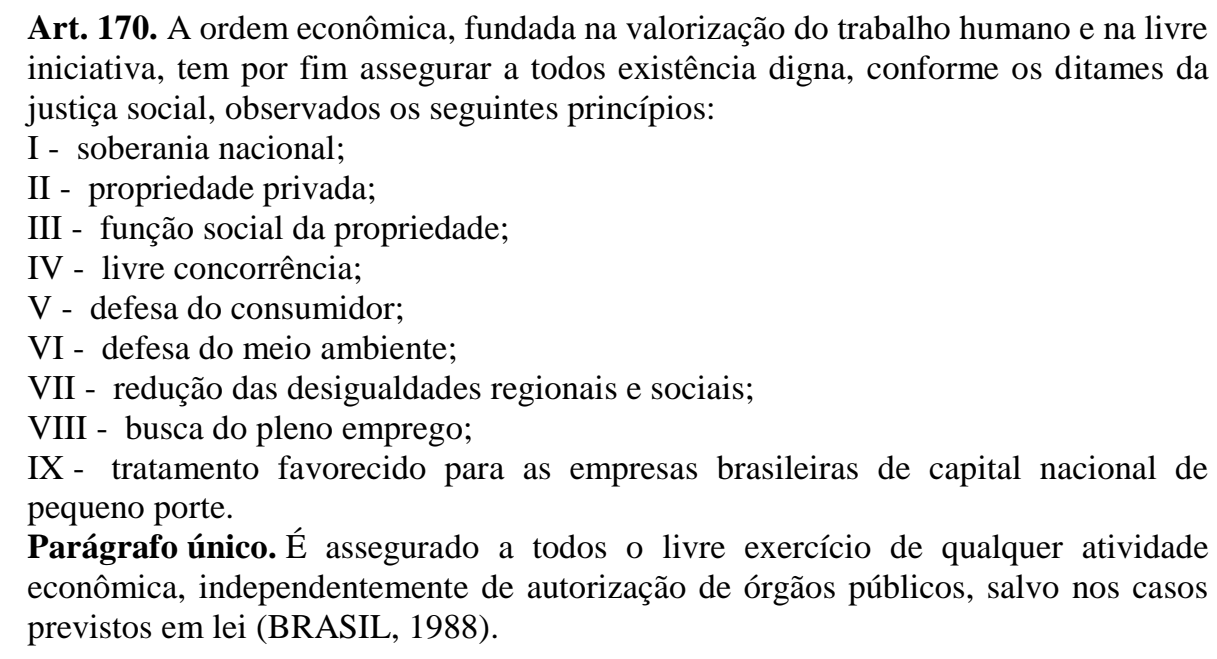

Visto a partir desta ótica, é possível perceber uma grande consonância entre os princípios da atividade econômica estabelecidos pela $\mathrm{CF}$ e os preceitos que caracterizam a empresa social, logo, mesmo não havendo legislação a respeito, suas atividades e função encontram-se amparadas legalmente.

Cabe destacar os $\S$ III, $\S$ IV, $\S$ VI, $\S$ VII, $\S$ VIII e $\S$ IX citados anteriormente, que tratam justamente da garantia da função social da propriedade em qualquer atividade econômica, prezando pela livre concorrência em cada setor, pelo cuidado com o meio ambiente, pela busca da minimização das desigualdades sociais e regionais, o direito ao emprego digno e a atenção favorecida das empresas nacionais de pequeno porte (SANTIAGO; DE MEDEIROS, 2017).

Esses preceitos não só amparam legalmente a atividade das empresas sociais, como também exigem que as demais empresas agreguem em suas atividades a função social. Isso porque o Estado tem grandes deficiências em suprir a população em seus direitos fundamentais, logo as empresas são incumbidas de cumprir sua função social, de modo a preencher as lacunas sociais (NERY JUNIOR; NERY, 2009).

Assim, por iniciativa própria ou não, tais empresas desenvolvem projetos e criam medidas internas com fim para o bem social ou financiam fundações e associações para que cumpram esse papel - na maioria dos casos essas são as empresas ou os negócios sociais. São 
estas que promovem o bem social, a dignidade e os direitos fundamentais às pessoas menos favorecidas da sociedade (MÉO, 2014).

\section{DIREITOS HUMANOS E A EMPRESA SOCIAL}

Ao tratar da preservação da dignidade, do trabalho, da subsistência, da inclusão social da pessoa, as empresas sociais acabam que, simultaneamente, reforçando não somente os princípios fundamentais previstos pela Constituição Federal do Brasil, mas, num sentido mais amplo, elas ajudam a garantir os Direitos Humanos a todas as parcelas da população, especialmente as mais necessitadas.

Isso porque, de acordo com Piovesan (2017):

O Direito dos Direitos Humanos não rege as relações entre iguais; opera precisamente em defesa dos ostensivamente mais fracos. Nas relações entre desiguais, posiciona-se em favor dos mais necessitados de proteção. Não busca obter um equilíbrio abstrato entre as partes, mas remediar os efeitos do desequilíbrio e das disparidades. [...] (PIOVESAN, 2017, p. 57).

Logo, o trabalho desenvolvido pelas empresas sociais em função dos menos favorecidos vem de encontro com os preceitos dos Direitos Humanos, de modo a promover a plenitude da vida humana às pessoas mais necessitadas. Isso é consonante também com os princípios estabelecidos pela Constituição Federal de 1988, que, embora trate dos Direitos Humanos a partir de diversos termos - como direitos fundamentais, direitos individuais, direitos naturais, etc. - têm tais direitos garantidos também em suas determinações, sendo os mesmos um de seus pilares fundamentais para o respeito à dignidade humana (SARLET, 2018).

Isso principalmente no que tange os Artigos I, II, XXIII, XXVI, XXV e XXIX que tratam: da igualdade, dignidade e liberdade de direitos, da vedada distinção ou preconceito entre os seres humanos devido a qualquer razão, da liberdade religiosa e de crença, do direito à instrução, das condições e recursos fundamentais para a vida e o bem-estar (alimentação, moradia, trabalho, etc.) e dos deveres de contribuição com a comunidade, respectivamente (ONU, 2009).

O trabalho desenvolvido pelas empresas sociais e demais instituições em geral mostramse de extrema importância nesse sentido, pois, quando o Estado mostra-se falho em atender e prestar assistência aos mais necessitados, elas acabam prestando esse serviço, seja integrando essas pessoas no mercado de trabalho, instruindo-as a uma profissão, orientando-as ou mesmo facilitando o acesso das mesmas aos serviços básicos como saúde, saneamento e educação. 
Mesmo diante das vantagens destacadas das atividades das empresas sociais e seu crescimento no Brasil, há de se salientar que muito se discute acerca da regulamentação legal de tais atividades. Entretanto, Bornhausen (2017) chama a atenção para os entraves jurídicos que embasariam tal regulamentação.

O autor destaca juntamente com a regulamentação viria já de início a burocratização dos processos como uma empresa de fato. Além disso, há de se considerar também que a regulamentação de empresas de caráter e funções sociais abriria caminho também para atos ilícitos como desvio de verbas, sonegações de impostos e corrupção tendo em vista as falhas existentes nos sistemas de fiscalização do Estado (BORNHAUSEN, 2017).

Tendo isso em vista, as empresas do setor privado têm também uma grande responsabilidade social que em alguns casos ultrapassa a dimensão de alguns Estados. Assim, cabe a tais empresas também a responsabilidade da função social - seja por iniciativa própria ou através de investimentos em empresas sociais. Dessa forma, o crescimento e ampliação das empresas sociais passa a estar relacionada mais com o setor privado do que com o Estado, sendo atribuída por este último o papel de cobrar e fiscalizar as ações para o bem-estar social da população (DA SILVEIRA; SANCHES, 2015). 


\section{CONSIDERAÇÕES FINAIS}

O objetivo do presente trabalho foi determinar a importância da empresa social no âmbito da manutenção dos Direitos Humanos. Assim, com o estudo realizado, notou-se que a disseminação das empresas sociais nos países emergentes tem se tornado uma crescente tendência.

Isso porque, nesses países, há uma busca constante por mecanismos e formas de minimizar as disparidades sociais, seja no âmbito do trabalho, da educação ou da economia. Percebe-se que, nesse sentido, os negócios ou empresas sociais têm se mostrado como um desses mecanismos, bastante eficientes e práticos (YUNUS, WEBER, 2008).

As empresas que promovem atividades de cunho econômico para arrecadar fundos com o objetivo do bem social no Brasil não possuem uma definição jurídica específica, sendo tratadas como cooperativas ou associações. No país, são comuns associações que desenvolvem produtos artesanais feitos por pessoas carentes, cujo lucro é revertido para suas comunidades. Outro exemplo é a produção de bens ou serviços por pessoas hospitalizadas, encarceradas ou portadoras de deficiência, cujo lucro também é revertido para tratamentos ou para promover melhorias nas condições de vida dessas pessoas (MÁRQUEZ; REFICCO; BERGER, 2010).

As possibilidades de empresas sociais são as mais diversas possíveis, especialmente em um país tão repleto de desigualdades sociais e pessoas necessitadas de assistência. Nesse sentido, esse tipo de negócio oferece a essas pessoas não só os itens necessários para sua subsistência, mas oportuniza trabalho digno ou o aprendizado de uma nova profissão. Isso por si só pode promover mudanças substanciais na vida de indivíduos em situação de vulnerabilidade social.

Diante do que foi visto, pode-se concluir que a missão das empresas sociais, seja qual for o seu setor de atuação, pode colaborar e favorecer uma vida mais digna a quem necessita, e, ao mesmo tempo, colaborar com a garantia dos direitos fundamentais a essas pessoas, através do acesso ao trabalho, a uma renda justa, à profissionalização e aos demais meios de promoção da inclusão social e da dignidade humana. 


\section{REFERÊNCIAS}

ABU-SAIFAN, Samer. Social entrepreneurship: definition and boundaries. Technology innovation management review, v. 2, n. 2, 2012.

ASHOKA EMPREENDEDORES SOCIAIS E MCKINSEY, INC. Empreendimentos sociais sustentáveis: como elaborar planos de negócio para organizações sociais. São Paulo: Peirópolis, 2001.

BERTONCINI, Mateus Eduardo Siqueira Nunes; MARKOVICZ, Silvia. O princípio da dignidade da pessoa humana e a responsabilidade social das empresas privadas. Revista Juridica, [S.1.], v. 2, n. 29, p. 375-405, dez. 2012. ISSN 2316-753X. Disponível em: <http://revista.unicuritiba.edu.br/index.php/RevJur/article/view/529/413>. Acesso em: 17 abr. 2020. doi:http://dx.doi.org/10.21902/revistajur.2316-753X.v2i29.529.

BORNHAUSEN, Roberto Althoff Konder. Desafios Jurídicos dos Negócios de Impacto Social no Brasil. Trabalho de Conclusão de Curso (Curso de Graduação em Direito) - Universidade Federal de Santa Catarina, Florianópolis, 2017.

BRASIL. Constituição da República Federativa do Brasil. Brasília: Senado Federal, Centro Gráfico, 1988.

COMINI, Graziella; BARKI, Edgard; AGUIAR, Luciana Trindade de. A three-pronged approach to social business: A Brazilian multi-case analysis. Revista de Administração, v. 47, n. 3, p. 385-397, 2012.

DA SILVEIRA, Vladimir Oliveira; SANCHES, Samyra Haydêe Dal Farra Naspolini. Direitos humanos, empresa e desenvolvimento sustentável. Direito e Desenvolvimento, v. 6, n. 12, p. 145-156, 2015.

DAVISTER, Catherine; DEFOURNY, Jacques; GRÉGOIRE, Olivier. Work integration social enterprises in the European Union: an overview of existing models. Revue Internationale de l'Économie Sociale: Recma, v. 293, p. 24-50, 2004.

DEES, J. Gregory et al. The meaning of social entrepreneurship. Fuqua School of Business: Duke University, 1998.

DEFOURNY, Jacques. L'émergence du concept d'entreprise sociale. Reflets et perspectives de la vie économique, v. 43, n. 3, p. 9-23, 2004.

JOÃO, Iraci de Souza. Modelo de gestão da inovação social para empresas sociais. Tese (Doutorado em Ciências Contábeis) - Universidade de São Paulo, Ribeirão Preto, 2014. Disponível em: https://teses.usp.br/teses/disponiveis/96/96132/tde-16122014163807/publico/IraciSJoao_Corrigida.pdf. Acesso em: 20 fev. 2020.

JONES, Jennifer A.; KOENIG, Anne M. The effect of "socially moral" purchases on future financial donations. International Journal of Nonprofit and Voluntary Sector Marketing, v. 23, n. 4, p. e1614, 2018. 
KERLIN, J. Social Enterprise in the United States and Europe: Understanding and Learning from the Differences. Voluntas: International Journal of Voluntary and Nonprofit Organizations, v. $17, \quad$ n. 3 , p. 246-262, 2006. Disponível em: https://link.springer.com/article/10.1007\%2Fs00440-002-0236-0. Acesso em: 21 fev. 2020.

MÁRQUEZ, Patricia C.; REFICCO, Ezequiel; BERGER, Gabriel (Ed.). Socially inclusive business: Engaging the poor through market initiatives in Iberoamerica. Harvard University Press, 2010.

MARTINHO, Ana Luisa. As empresas sociais de inserção na promoção do emprego e inclusão social a partir de estudos de caso europeus. In: XVII Encontro Nacional de Sociologia Industrial, das Organizações e do Trabalho. Setúbal, 2018.

MÉO, Letícia Caroline. Empresas Sociais, Função Social da Empresa e Responsabilidade Empresarial Social. Revista de Direito Privado, p. 193-230, 2014.

MORAES, Alexandre de. Direito constitucional. 17. ed. São Paulo: Atlas, 2005.

NERY JUNIOR, Nelson; NERY, Rosa Maria de Andrade. Constituição Federal comentada e legislação constitucional. São Paulo: Editora Revista dos Tribunais, 2009.

OLIVEIRA, Edson Marques. Empreendedorismo social no Brasil: atual configuração, perspectivas e desafios-notas introdutórias. Revista da FAE, v. 7, n. 2, 2004.

ONU, ORGANIZAÇÃO DAS NAÇÕES UNIDAS. Declaração Universal Dos Direitos Humanos. UNIC/Rio/005, 2009.

PIOVESAN, Flávia. Direitos humanos e o direito constitucional internacional. Editora Saraiva, 2017.

ROSOLEN, Talita; TISCOSKI, Gabriela Pelegrini; COMINI, Graziella Maria. Empreendedorismo social e negócios sociais: um estudo bibliométrico da publicação nacional e internacional. RIGS: Revista Interdisciplinar de Gestão Social, Salvador, v. 3, p. 85-105, 2014. Disponível em: https://portalseer.ufba.br/index.php/rigs/article/view/8994/11596. Acesso em: 24 fev. 2020.

SANTIAGO, Mariana Ribeiro; DE MEDEIROS, Elisângela Aparecida. Função social e solidária da empresa: impactos na liberdade econômica versus benefícios no desenvolvimento nacional. Revista Jurídica, v. 2, n. 47, p. 99-122, 2017.

SARLET, Ingo Wolfgang. Dignidade da Pessoa Humana e Direitos Fundamentais: Na Constituição Federal de 1988. Livraria do Advogado Editora, 2018.

SEBRAE. Diretrizes estratégicas para Atuação do sistema SEBRAE no mercado de negócios sociais. Serviço Brasileiro de Apoio às Micro e Pequenas Empresas - SEBRAE, 2013. Disponível em: https://www.sebrae.com.br/Sebrae/Portal\%20Sebrae/UFs/SC/Anexos/NS\%20SEbrae\%20-\%2 0Diretrizes_estrategicas.pdf. Acesso em: 23 fev. 2020.

SOUZA, Crisomar; DA SILVA, Leandro Storini Modesto. Estratégia na base da pirâmide: um 
exemplo de competitividade nas empresas brasileiras. Caderno de Administração. Revista da Faculdade de Administração da FEA, v. 13, n. 1, 2019.

YUNUS, Muhammad; WEBER, Karl. Um mundo sem pobreza: a empresa social e o futuro do capitalismo. São Paulo: Ática, 2008. 